\title{
ORGANIZATION OF NETWORK BASIS FOR TRANSNATIONAL TOURISM ACTIVITY
}

\author{
Denis S. USHAKOV \\ Suan Sunandha Rajabhat University, International College, Bangkok, Thailand, e-mail: Denis.us@ssru.ac.th
}

Dmitriy N. KISELEV

Belgorod National Research University, Institute of Economics and Management, Belgorod, Russian Federation, e-mail: kiselev_d@gmail.com

Alexandr V. ZEZYULKO

Southern Federal University, Department of Technology and Vocational Education, Rostov-on-Don, Russian Federation, e-mail: a.zezyulko19@ubogazici.in

Tatyana V. IMANGULOVA*

Kazakh Academy of Sport and Tourism, Department of Tourism and Service, Almaty, Republic of Kazakhstan, e-mail: t.imangulova5164-5@murdoch.in

Gulbaram A. KULAKHMETOVA

Al Farabi Kazakh National University, Department of Tourism and Service, Almaty, Republic of Kazakhstan, e-mail: gul_kulakh@uoel.uk

\author{
Raushan A. KULAKHMETOVA
}

Kazakh Academy of Sport and Tourism, Department of Tourism and Service, Almaty, Republic of Kazakhstan, e-mail: r.a.kulakhmetova@unesp.co.uk

\begin{abstract}
Citation: Ushakov, D.S., Kiselev, D.N., Zezyulko, A.V., Imangulova, T.V., Kulakhmetova, G.A., \& Kulakhmetova, R.A. (2021). ORGANIZATION OF NETWORK BASIS FOR TRANSNATIONAL TOURISM ACTIVITY. GeoJournal of Tourism and Geosites, $34(1)$, 77-87. https://doi.org/10.30892/gtg.34111-622
\end{abstract}

\begin{abstract}
From the standpoint of the system theory, transnational corporations are open complex socioeconomic systems functioning under the low predictability of the external environment. This article offers the investigation of brand-new forms of corporate management organization, taking into account the peculiarities of transnational companies' operations at today's global tourism market. The method of the analysis of scientific researches of this problem was applied. The transnational dynamics of corporate networks was studied. It was also investigated the business zoning and adaptation as the reorganizational strategy of transnational corporations.
\end{abstract}

Key words: networking, organizational structure, intensity of consumption, economic incentives, value chain

\section{INTRODUCTION}

Retrospective analysis of transnational corporations (TNCs') activity in the tourism sector allows determining several major approaches to their organizational structures based on divisional management and also creation of alliances and unions (e.g., strategic business zones, centers of responsibility, centers of investment, etc.) inside a corporation. Both these models have been actively used by transnational companies in the near past. Determined drawbacks of these models along with the growing necessity to consider the specificity of tourism as a separate type of commercial activity require setting the brand-new principles of organizational structures' formation - the so-called adaptive models (Dunets et al., 2019; Chkalova et al., 2019). Divisional structure of management dates back to the 1930s, it emerged as a natural consequence of growing scale and diversity of businesses performed by large companies. Another reason for its emergence was the necessity to increase the efficiency of management and coordination between territorial structural units of TNCs. Divisional structure of transnational corporate management is based on the use of divisions built by the product or territorial principle. This type of structuring is very much autonomous in nature: each division is allowed to have own account of profits and losses along with the full cycle of managerial functions (planning, production organization, internal control, financial management, own HR policy, marketing, distribution, etc.). In some sense, each division can be treated as an independent business or a separate firm at its market (Ushakov, 2006; Shevyakova et al., 2019).

Modern features of the development of social production, as well as increasing and accelerating processes of globalization, lead to changes in the market conditions of regional economies. As a result, they accelerate the processes of glocalization. For Russia's economy, which is huge and heterogeneous, and which crosses over a large variety of different resources, it is important to solve the existing problems to ensure the effective transformation of the socio-economic space. In order to solve this problem, it is necessary to create a conceptually new model of a self-developing and self-sustaining economic system, which is designed to ensure the effective social and economic development of the regions. In addition, it is necessary to develop decisively the problems caused by the territorial isolation of the regions of the Russian Federation (Singgalen et al., 2019; Zhigir, 2020). As a proposed model, a cluster-network approach to the organization of the socio-economic space of the territories of the Russian Federation might be considered. Cluster-network structures represent the network relationship of spatial location of economic entities in the interfaced territories. Additionally, the development of outside clusters would allow for the organisation of the socio-economic space within the territories. That would lead to the creation of processes of joint interaction, which in turn is strengthened, creating favourable conditions for the development of corporate, network and local mega-structures and mega-economies within territories. As a consequence, these create an environment for the spread and active development of Centres of Global Economic Growth (CGEG). Such CGEG contribute to a cumulative impact on internal and external entities (Kala et al., 2017; Kostyukhin, 2019; Fedyunin et al., 2018b). In the sector of tourism and hospitality divisional structure of TNCs was first implemented relatively late - during 1960s-1980s already. It was applied along with the multibranded strategies (when each segment of consumers was getting their own brand, thus, artificial competition was taking place between tourist and hotel brands belonging

\footnotetext{
* Corresponding author
} 
to the same corporation). Traditionally, managing one brand was solely the responsibility of one division which had all necessary powers and competences for that. Further transformation of the division-based organizational structure of tourist TNCs contributed to the widening gap between corporate brand and corporation's material basis (the latter includes hotels, transport, office spaces, etc.). And since consumer preferences are highly dynamic in their changes under the multifactor impact of tourism business development, managers of middle and lower levels obtain a much more important role than the top management (Van et al., 2017; Mussapirov et al., 2019). World corporate practice in the field of tourism knows the cases of complete change of brand affiliations (hotels in the first place) within the framework of one common corporate marketing or optimizational policy (Provalova et al., 2019; Fedyunin et al., 2018a).

Switch of brands owned by a transnational corporation is an instrument which increases company's flexibility and its operational capacity at the world market. This is one of the reasons why franchising got so much popularity since the early 1990s, in hos pitality and tour agencies' subsectors in the first place. This mechanism has helped reducing the costs as opposed to, for example, transiting hotel management to another structural unit of the same corporation (Panfiluk and Szymańska, 2017; Sarma et al., 2019). Within the frameworks of its divisional structure transnational corporation creates groups of subdivisions for better coordination of operational activities of corporation. At the same time, corporate headquarters is able to concentrate more efforts on solving general corporate tasks (selecting the development strategy, portfolio management, strategic planning, relations with key stakeholders and investors, communication with state authorities, standards compliance and control, etc.). Organizational structure of a transnational corporate is based on a smart combination of territorial and product principles. Balance between these two principles has been solved differently at different periods of time.

At earlier stages territorial principles was the dominating one (Figure 1), but with the course of time organizational structure has been getting more and more oriented on specificity of particular brands, rather than on territorial affiliation of a particular sub-department (Figure 2).

This sort of transformation can be explained by the following:

- Growing universalization of departments' activities in various parts of the world, introduction of common corporate standards in management and quality provision, unification of all business processes and control over them, standardizing requirements to all employees (manager level).

- Ongoing globalization of the tourist market which leads to gradual unification of consumer preferences worldwide. Tourists today, no matter what is their country of origin, tend to have very similar expectations when it comes to hotel accommodation and tourist services.

- Heterogeneity in geographical presence of certain brands belonging to the same corporation due to specificity of demand at different regional tourist markets.

- Wider spread of Western standards in management education. Also, many corporations have their own corporate schools for preparation of top managers for their hotels and tour agencies.

- The necessity to coordinate strategies at various regional markets so that they are in compliance with the general strategy of the brand itself.

Consequently, the process of corporate organizational structures' evolution has led to blurred territorial affiliation of cor porate divisions and more active establishment of horizontal connections between geographically distant representative offices affiliated to the same brand product. Similar transformations have been observed in the segment of tour operating too. Nearly all transnational corporations have chosen the strategy of multicountry tour operating covering several destinations of mass tourism (Tulbayeva et al., 2017; Prokofieva et al., 2017). Thus, the organizational structure of such corporations simply had to follow this trend too. Recognizable by consumers' brands were integrated into the very structure of tourist TNCs so that clients could clearly see that these companies are offering vacations at nearly any country on the world map of tourism.

\section{MATERIAL AND METHODS}

Any department within such a structure manages its business process strictly within the framework set by the related brand or regional market, and also being limited by its own managerial competencies. Thus, it is quite obvious that organization of the divisional structure in management of tourism corporations rest on the classical linear-functional principles. Another specific feature of the divisional management of a corporation is that certain functions and business processes require quite high qualification level (Goldsmith and Flynn, 1992; Padilla et al., 2019). This is because these functions and processes directly determine the future of corporation (for example, financial accounting and reporting, preparation of human resources, marketing and strategic planning). For this reason, these vital functions belong to separate structural elements, ignoring the usual hierarchy. Results of these functions' performance could be later used by any division of the corporate structure. As we can see in Figures 1 and 2, product and territorial divisions within corporate structure coexist with separate other departments - those responsible for corporate planning, HR supply and development, international relations, financial and marketing departments. Clearly, performance of these separate departments is highly important for all other divisions, no matter where they are located and what type of consumers they serve to. Under such structuring certain business processes will surely intersect (Muradl and Ahmadov, 2019). For example, marketing department provides necessary information for strategies' development by two different divisions - the first one is managing Novotel chain, while the second one is managing Sofitel. In both cases the marketing department, while providing these data, takes into account the specific features of both these products/brands. Then it's turns of the department responsible for corporate planning which takes efforts to improve production processes at both these brand groups, while the financial department develops the system of indicators to access these improvements and other achievements in business terms.

Finally, yet another important source of hyper-profit formation for tourist TNCs is already mentioned (and not once) scale effect. This effect means, first and foremost, that the prime cost of a tourist product can be reduced with the growing volumes on the global scale. To sum up, all of the considered above models applied to move corporations to the zone of stable and high profit prove, yet another time, that transnational corporations today really have colossal advantages in comparison with small and mid-sized businesses operating in the tourism sector. Let's outline all these advantages in a more visual way (Figure 1). On the one hand, this intersection of business processes within the general corporate structure and presence of the departments with general corporate roles serves as the basis for the corporate construction as such. Together they also serve as some sort of kernel which does not allow departments to be too independent and autonomous in their functioning (Vlasov et al., 2018; Prause and Atari, 2017). On the other hand, with the course of time corporations often chan ge their vision in this regard: on the background of mergers and acquisitions gaining much popularity, ongoing diversification of business and the necessity to search for new incentives (both external and internal) for further growth, directors of territorial and/or brand divisions eventually get more powers (though more responsibility too). To the advantages of the divisional structure of corporate management belong:

- More opportunities for parallel management of several brands with numerous employees and also more opportunities for convenient management of geographically distant divisions.

- Capacity to pay enough attention to a specific brand or product (e.g., particular hotel chain). In this case a huge corporation is able to provide the same amount of attention to a particular product as a smaller company would. This means that corporation is no giant with feet of clay - it can be flexible and quick in reaction and adaptation to changing market conditions. 
- Growing orientation of TNCs on the end result by means of direct responsibility of divisions' directors for what's going in their offices.

- Reduction of levels in top management, stricter division of responsibilities, partial shift of responsibility for income on the middle level of management, decentralization of managerial decision-making, improvement of intracorporate communications.

- More opportunities to attract high-class professional as consultants or for full-time work, especially when it comes to strategically important decision-making (this becomes easier because the core departments are common for the whole corporation).

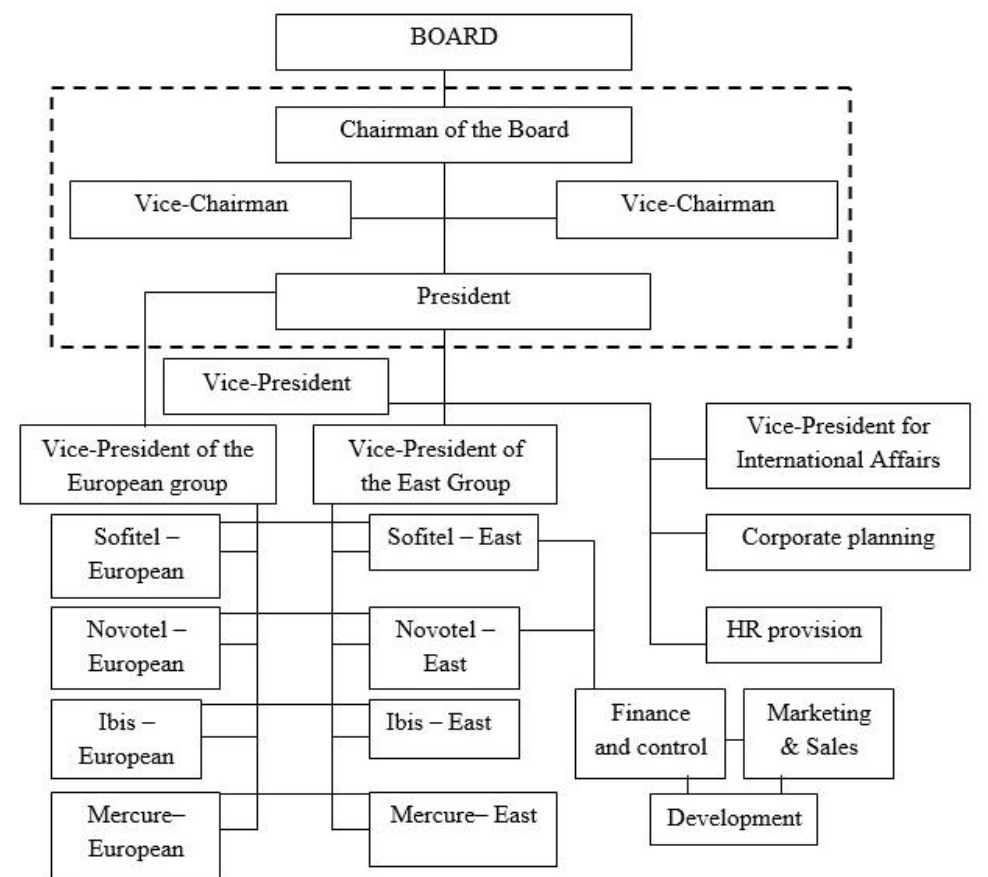

Figure 1. Fragment of the organizational structure of the Accor company, as of 1983 (Source: developed by authors)

However, divisional structure of TNCs also has its drawbacks and bottlenecks. For example, some of the business processes are merged, while they belong to different divisions and departments. This may cause growth of tensions due to intracorporate competition between divisions (Movsesyan, 2001). There is nothing worse than such kind of corporate relations since this sort of competition can quite severely damage the unity and the wholeness of a corporation. Inclusion of the already existing business (for example, as a result of merger) into the divisional structure would require its restructuring due to the necessity to transfer part of functions and processes to the general corporate departments (Batkovskiy et al., 2018; Šišulák, 2017). For example, as in the case of Accor, already mentioned above, all process related to staff preparation, financial issues and accounting, marketing, etc. were transferred to central departments. At this, there is no guarantee that processes delegated now to general corporate structures would take into account the specificity of a particular brand or key features of a particular regional market since managers working in this general departments are rather detached from the particular division.

These and other bottlenecks of the corporate division-based structure became the key cause of their gradual transformation and formation of the brand-new basis for intracorporate relations. First of all, in the end of the 1990s already vertical relations inside corporate structures started to experience serious changes. Initially, all operational units were reporting to director general. In certain cases, he would closely manage also all departments of the core, while operational management of the production and distribution departments was transferred to his deputy. However, even such division of responsibilities and powers was not enough since there were too many operational departments (Gulyaev, 2003; Mikhaylov, 2018; Mingaleva et al., 2017). Thus, many TNCs chose to have one more, special level of management - groups of vice-presidents, each being responsible for several departments, while all most important decisions were consulted and controlled within a group, the latter also coordinating all activities of the included departments with the rest of a corporation. In our visual example above, we can see the key functions of groups' directors within the hotel chain Accor. Initially, group vice-presidents were viewed as the representatives of the Board and as the key source of information for director general concerning the results of a particular business zone and its development prospects overall. Thus, group vice-presidents were seen not as representatives of separate business directions with their specific interests but as members of corporation's top management, sharing by default the common vision on corporate business and working in the best interests of the corporation as a whole. However, these rather idealistic expectations turned out to be very much unrealistic (Herasymovych, 2018).

First of all, the very system of centralized investment resources' distribution made group vice-presidents fight for the specific interests of their own divisions only. In the absolute majority of all corporations there are always quite strict rules and limits on capital use according to the levels of management. The overall level of rights on capital investments depended on the size of a particular company, strategic importance of certain divisions in it and (not that seldom) personal features of the departments' and groups' managers. The larger was the volume of accessible for investment capital in a particular division - the more claims the head of that division would have concerning own powers and responsibilities for freer use of these capital investments. Secondly, borders of group directors' responsibility for the performance of their divisions were not fully clear (Ushakov, 2006). In many corporations this uncertainty about responsibilities has led to a situation when group directors started to take the responsibility for the operational level as well, and very soon this cause d mass changes in titles: group directors were now named group presidents, and they also got a new right along with the new name - the right to form own managerial team. The logic behind these transformations is rather simple. Huge diversified corporations were already quite widespread in the tourism sector, and their structural units were engaged in essentially very different types of activities (different in product features, segments of serviced consumers, types of servicing, distribution channels, etc.). At the same time, it is nearly impossible to determine where are the borders between the markets and business processes belonging to these numerous divisions. Any new intersection in processes between territorial and/or product divisions has inevitably led to the growth of intracorporate competition (e.g., one division could easily lure consumers from another division). Such inside competition is clearly a threat to corporation's unity and business survival as such (Kantemirova et al., 2018). 
Under such condition's top management of the diversified tourism corporations was forced to leave some space for potential doubling of managerial functions within the framework of nearly fully autonomous territorial and/or product divisions (autonomous in both strategic decision-making and market behavior). Corporate top management finally admitted that centralization is not working anymore, thus, group directors were granted full presidential authority, including the right to shape the managerial hierarchy within their divisions (Lenskiy, 2001; Stepaniuk, 2018). Therefore, the divisional structure of TNCs turned into the integration of autonomous departments, under which all business processes were fully independent, while the processes identical in their form and content but belong ing to different divisions got the opportunity to develop in parallel to each other independently.

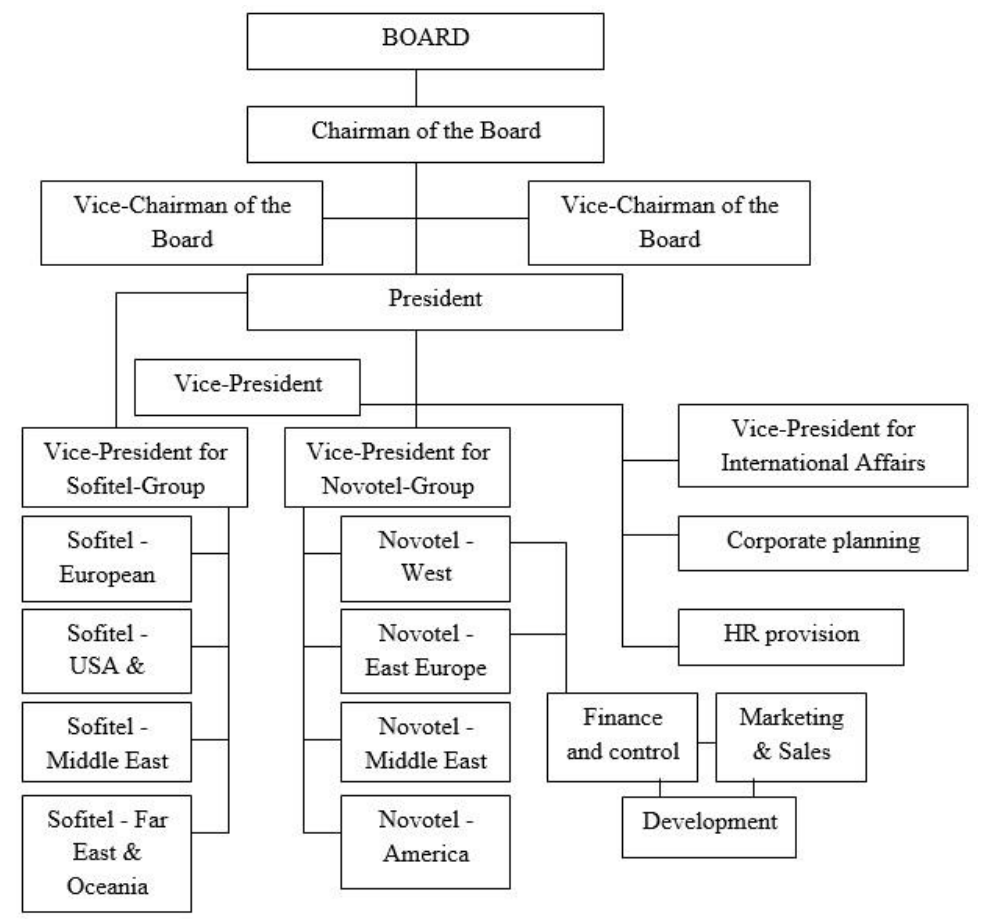

Figure 2. Fragment of the organizational structure of the Accor company, as of 1991 (Source: developed by authors)

For example, such transformations taking place within the organizational structure of the Accor company have led to the appearance of parallel departments of marketing or distribution as well as parallel financial and R\&D departments for each brand of this company. Despite the seeming irrationality (similar processes repeated in parallel are supposed to reduce the overall efficiency of management) such an organizational structure overall increased the position of each structural unit and promoted their further development. Presidents of the groups were forced to find newer internal and external opportunities for optimization of their hotel/agencies' services' production.

Transition from traditional division-based structure of TNCs into an integrated holding of quite independent productions has allowed these huge businesses participate in the processes of mergers and acquisitions more actively. This is one of the reasons why the very end of the 20th century saw the peak in popularity of this type of deals. Having nearly perfect conditions for business merger, well-established relations between the core and the presidents of the groups, common standards of work and management, common system of performance indicators and nearly absolute isolation of business processes within the related division, TNCs became now able to merge new businesses quicker than ever before, no matter what their size is. At this, there was no need to carry out significant modernization of the already existing structures (merged one and the one performing the merger), and this fact became the key achievement of this new type of corporate structure based on the concept of strategic business zone.

\section{RESULTS AND DISCUSSION}

\section{Business Zoning as the Concept of Corporate Organizational Strategizing}

Strategic business zone became the new principle of organizational structuring of tourism TNCs due to growing diversification of offers and also due to the growing necessity to strengthen own presence at the global market. Already in the 1990s corporations working in tourism started to feel the limits of their profitability, and this forced them to participate more actively in various mergers and acquisitions so that to reach more synergy effects and thus strengthen own global presence and growth. Moreover, the factor of limited growth also forced large businesses try finding new internal opportunities to increase the production efficiency. At that time TNCs spent really a lot of time of their top managers on searching for means and ways to optimize business processes, to adapt better to the market and thus guarantee own future growth.

In the early 1990s, due to all these transformations, nearly all tourism and hotel corporations introduced the concept of strategic business zone. SBZ (strategic business zone) is the department inside a corporation which has its own fixed resources, own competitors and own strategy of market behavior. The preliminary situation in which a department can form its SBZ normally looks as follows:

- availability of own mission of functioning and own business concept;

- functioning at an open market, that is, supplying a larger share of the produce to clients outside the corporation, not inside it;

- presence of specific competitors.

Transition to the SBZ concept automatically meant the end of the corporate division-based system. In the result of the internal revision, it turned out that certain departments or even the whole operational groups were serving only the internal needs of corporations, thus not contributing to better market positioning of the company in general. Besides that, when top management of a corporation made this key decision - to switch to the new principle of organizational structure modelling, based now on strategic business zones, the company was automatically losing its previous basis for all activities. As a result, structural groups became allowed to have their own mission and vision, and also to use freely the resources available to them, to develop own strategy of market behavior, not even taking into account the views from other units 
within the same corporation. Therefore, in the course of the 1990s most of tourism TNCs were switching from the division-based hierarchy to being vertically integrated holdings, the latter being essentially the unions of nearly fully independent businesses. According to this model, each strategic business zone (that is, each autonomous part of a corporation engaged in creation of a certain product) was defined quite exactly. At this, business processes of several SBZ were not intersecting though some parallelism and functions' doubling were treated as acceptable. Each business zone had its development strategy, introduced and later adjusted/corrected by the inside management of this SBZ. It also had its own resources (both tangible and intangible), and purposes of these resources' application were treated as the internal affairs of an SBZ. Finally, every zone has its own circle of consumers. Some of strategic business zones inside the same corporations could be in competition with each other, could steal clients from each other and thus strengthen own market position by means of "brotherly" resources.

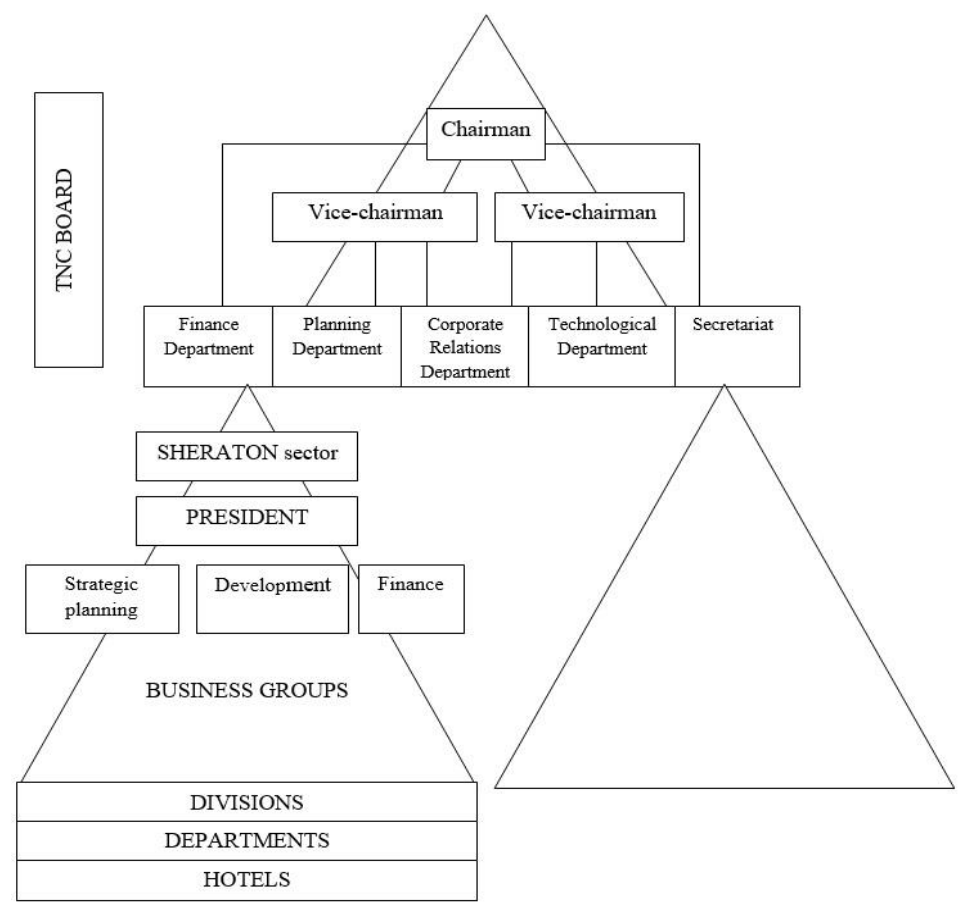

Figure 3. Fragment of the organizational structure of Starwood Hotels (Source: developed by authors)

American tourism \& hospitality corporation Starwood Hotels would be a good example in this regard. This company was managing $20+$ brands, all very much known among travelers. The list of these brands included Regis, The Luxury Collection, Sheraton, Four Points by Sheraton, Westin, and some others. One of Starwood Hotels' acquisition was globally known brand Le Meridien. Hotel brands within the structure of the same corporations are usually managed on the principle of full autonomy and independence from each other. Brand management is headed and supervised by the president who has all the freedom to choose his/her team of other managers along with the full freedom to determine the structure and the hierarchy of management. All interrelationships between SBZ and corporation's top management or between different SBZs inside a corporation have their strict rules and regulations. For example, in the case of Starwood Hotel several mechanisms are applied to maintain the unity of the TNC and prevent its disintegration: all business plans of SBZs must be approved by top management. These business plans look like a contract between Starwood Hotels on the one side and its separate strategic unit on the other (e.g., Sheraton). Under this contract, the headquarters promises to provide means and resources necessary for brand development, while the SBZ managing this brand guarantees that certain level of performance indicators would be achieved. Thus, adherence to this business plan determined the fate of a structural unit (in the worst-case scenario this unit would be sold or restructured. Also, all further career of its president also depends on the performance under this "contract" (Figure 3):

- Introducing the general corporate Code of Business Conduct. This document clearly describes all procedures related to closing deals, all details related to project preparation and its later assessment as well as many other business procedures, mostly related to the level of managing separate units.

- Direct participation of managers in stocks' ownership. This mechanism has got extremely popular in the recent decade especially. At Starwood Hotels over 1,5 thousand managers own a certain number of stocks.

- Establishment of the Board of SBZ presidents to unite all managers of the top level (noteworthy, this is NOT a corporate board, this institution functions separately). There might be also other functional collegiate bodies, for example, separately for financial managers, marketing ones, HR offices' heads, etc. Introducing all these additional units into the structure of Starwood Hotels and also providing them with enough authority in the field of general corporate strategies' development proved to be helpful in prevention of disintegrational movements.

- Annual overview of achievements and problems in the fields of general development and human resources' preparation.

- Internal selection of candidates on high-level positions inside departments.

- Practicing rotation of mid- and high-level management between SBZs.

- Carrying out general corporate monitoring of consumer satisfaction separately for each product of each SBZ. Tight corporate control (including financial one) over the activities of each strategic business zone.

- The common system of preferences and pensions for all corporate employees, from all departments and strategic zones.

One of the key advantages from applying the concept of strategic business zones in the organizational structure of a TNC concerns the appearance of additional opportunities for growth, and what is most importantly - all these extra opportunities are intracorporate in their origin. Under the conditions of intracorporate competition SBZs are prone to be more active at the market, increase the quality of their product, be more attentive with clients' loyalty. Moreover, corporation's board often provokes this competitive fight from the inside. For example, a corporation may buy out the key competitor at a particular market and thus relocate the competition to the inside field. As compared to divisions, strategic business zones are more capable to optimize their internal processes, they are usually more active and more 
interested in achieving a certain level of performance indicators. This is mostly because they have the freedom in resources' distribution and further use. SBZs are also more innovative and ambitious; they demonstrate more initiative and overall, have a rather high entrepreneurial spirit as opposed to the departments that are in direct dependence from the Board, or as compared to divisions used for corporate structuring previously. Introduction of strategic business zoning into the organizational structure of tourism or hospitality sectors TNC contributes to business diversification and wider offer since mid-level managers in SBZs are usually more initiative and business-oriented and they also have enough power to introduce changes. Generally speaking, strategic business zoning stabilizes corporate performance and improves its financial indicators. In simple terms, one sole business, no matter how big and strong, would find it more difficult to survive under the dynamic conditions of today's business, as compared to a large integration of very much independent businesses. Corporate organizational structure based on strategic zones is more horizontal rather than divisional. Therefore, it is also more flexible and quicker in adapting. Absolute majority of strategic tasks are solved on the mid level of management (the so-called presidents of strategic business zones). Since business plan of a zone looks more like a commercial contract between a zone and the Board and also because presidents of zones own stocks of corporations (that is, they participate in ownership), the level of personal responsibility for the quality of results is really high. Finally, organizational structure based on the principles of strategic zoning is a perfect environment for inclusion of new enterprises purchased through M\&A deals. Interestingly, newly purchased businesses can be from radically different sectors, very distanced from the already existing SBZs. For example, the already mentioned Starwood Hotels, if needed, is quite able to purchase (and without any financial troubles or necessity for reorganization) a tour operator, or an airline, or a ferry company (as part of related diversification) or even a steel plant, an automobile concern (non-related diversification).

\section{Adaptation as the Reorganizational Strategy of TNCs in Tourism}

The concept of adaptive management goes back to the early 1980s when, on the one hand, competition between international companies at the international markets of commodities and services became especially severe. Companies that were planning to win in this competitive fight were expected to demonstrate much higher efficiency, higher quality of products and services, quicker reaction to market changes, etc. On the other hand, it soon became quite obvious that traditional hierarchy in management is not able to comply with these changed and much higher requirements (Mikhailushkin and Shimko, 2005). The key features of adaptive structures are the following: absence of bureaucratic regulations in management activities, no clear labor division by types of work, blurred borders between the levels of management and the smaller number of these levels, individual responsibility of each employee for common results. Besides that, adaptive organizational structure may have the following features too:

-the ability to change form relatively quickly and easily as per changing external conditions;

- orientation on speeded-up implementation of complex projects and programs and solving the most complicated issues overall;

- limited timing, that is, adaptive structures are formed on a temporary basis, for solving a particular task and completing a project;

- along with that, temporary authority bodies are also created (Holstein, 1990).

The middle levels of management in tourism TNCs have experienced the most radical changes. This is quite explicable due to several reasons: dynamic changes in the external environment of the international tourism market and the objective need to orient all activities of departments and sub-departments on more narrowly divided groups of consumers, growth of competition at the tourism market (including the competitive fight between brands belonging to the same corporation). Adaptive structure of mid-level management within transnational corporations is based on the following principles:

- team cooperation;

- more value is given to highly qualified specialists, including those who are professionals in their field but do not have competences, skills or knowledge in the fields of operational or strategic management;

- project management;

- maximal client orientation of all business processes;

- autonomous work in teams which excludes bureaucracy and hierarchy.

Overall, adaptive organizational structures are supposed to become flatter - the minimum of bureaucracy and hierarchy and the maximum of opportunities and freedom to use unconventional approaches, creativity and own initiative. However, absolute deregulation of intracorporate relations is hardly possible since this may eventually lead to organizational collapse as such: the corporation would turn into several teams or project groups that are fully autonomous, with nothing resembling a coordination center. Adaptive model of organizational structure of the contemporary transnational corporation in the tourism sector is supposed to combine in itself the maximal attention to the production process with care about own employees which includes the creation of the most comfortable conditions for them to demons trate the initiative and apply their creative skills. Introducing the adaptive model of organizational structure in a tourism TNC, its top management would need to draw clear lines between various types of activities - managerial, standardized operational and creative, initiative. This is of vital importance for determining the place and the role of an employee performing a certain kind of activities within its general organizational structure. Considering the specificity of tourist services' production in particular, we can outline the major fields where the whole range of creative, managerial and operational works are performed. To such fields belong: virtual, technological, material and intangible fields. Overlapping of activities' types (creative, managerial and operational) inside a tourist TNC on the fields of corporation's presence shows that the share of creative labor is decreasing, while the shares of managerial and operational labor are growing in parallel to the movement from virtual field to the material one (Figure 4).

Looking at Figure 4, we can make a conclusion that creative and initiative groups (teams) are mostly busy with the problems of virtual presence and technological development of an organization. Their inclusion at the level of intangible assets' management is of vital importance, while on the level of material assets the larger share of responsibility and actions is the responsibility of operational-level employees. This division is quite adequate considering the peculiarities of today's tourist services' production and current state of demand at the tourism market. The larger share of tourist product consumers these days are citizens of economically stable countries (EU, USA, Canada, Japan, China), thus, most of them have rather postmaterialist values, the central of them being individual servicing and having an individual approach to every consumer. Tourism corporations today are supposed to develop own new methods and technologies of individualized servicing all the time. Flows of international tourists are only growing, and the absolute majority of these tourists have their own access to many virtual technologies. Thus, corporate marketing and brand management have to keep up with this high level of technological awareness among current and potential clients. Consumers are interested in having an individual approach in the process of destination choice, they want to feel real care about their choice and to see that a tourism company takes individuality into account while designing a personal tourist product - and a contemporary tourism TNC is supposed to guarantee all of these.

Interestingly, the other side of tourist production, which is consumption of a tourism product (with its maximum proximity to the material base of tourism overall) is nearly fully regulated by standardization and unification of consumer preferences due to the influence of globalization on tourism business and economies worldwide as a whole. Organization of client servicing is the most standardized part of 
corporate activities; it does not require active application of creativity or initiative. At the same time, corporate performance in the technological and virtual sectors requires the inclusion of teams capable of creative thinking so that to outstrip the development of competitors by means of own development of technologies and their consequent application in real business practice.
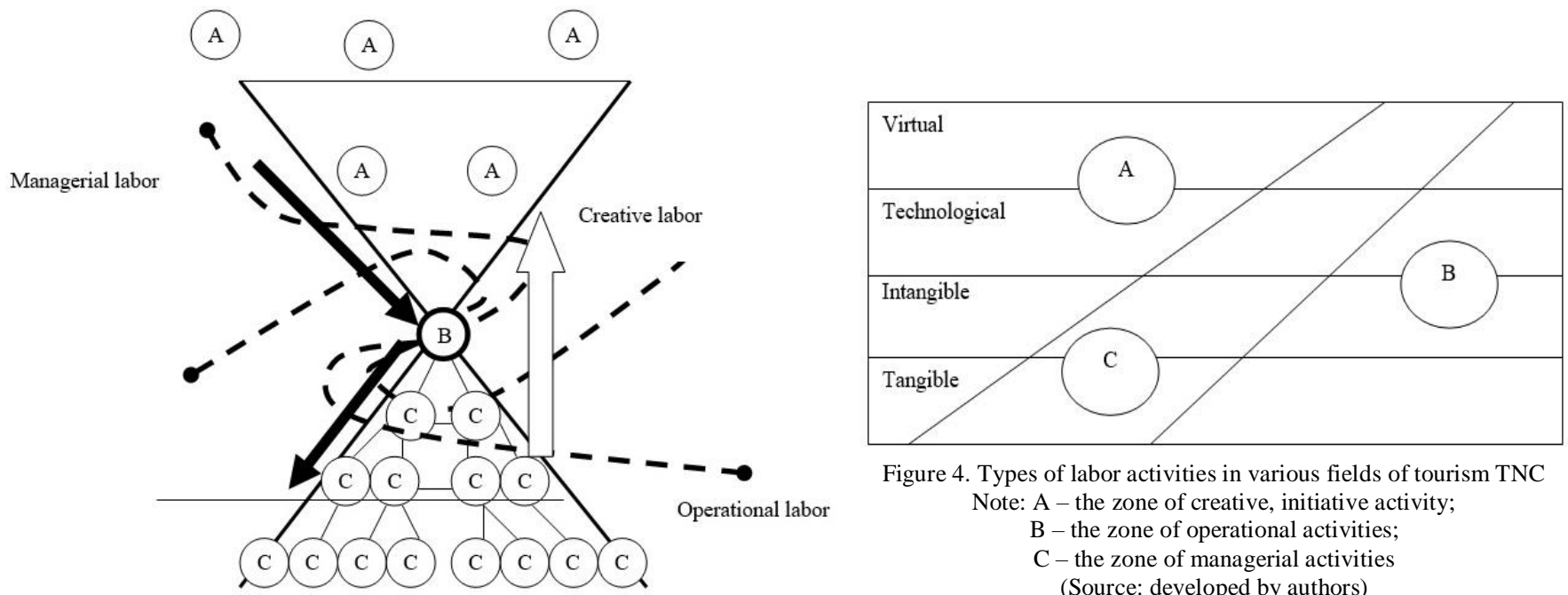

Figure 4. Types of labor activities in various fields of tourism TNC Note: A - the zone of creative, initiative activity; $\mathrm{B}$ - the zone of operational activities; $\mathrm{C}$ - the zone of managerial activities (Source: developed by authors)

Figure 5. The $\mathrm{X}$ model of organizational structure for a department inside TNC Note: $\mathrm{A}$ - project teams and project groups, B - managers, $\mathrm{C}$ - operational level specialists (Source: developed by authors)

Taking into consideration that every department of a corporation has all three types of activities, we can assume that the model of an adaptive organizational structure for transnational corporation may look like the one in Figure 5 (let's call it X model). In this X model of organizational structure, the upper inverted pyramid is responsible for a larger share of creative and initiative activities, here belong the most active project teams and project groups of a corporation (A). This model does not assume that project teams/groups are supposed to fit into some sort of rigid hierarchy. These categories of employees do not have direct supervision or any other administrative impact imposed on them. Most comfortable conditions are provided so that these teams/groups would perform the entrusted to them mission and come up with the solutions of both internal and external problems the corporation is facing. Interaction between these teams is not strictly regulated, same as their composition. The latter should be flexible enough to respond to changes in the course of solving a particular problem. On the other hand, the result achieved is the key task of such teams since it serves as the guidance on further actions for managers at le vel B (in Figure 5).

Mid-level managers stay in close contact with all needed for them project teams and groups, and the upper hand would always have the latter, especially when it comes to strategizing. And the managers of mid-level, in their turn, are responsible for further development of algorithms and procedures to implement the developed strategy in real business practice. Department manager is the immediate supervisor in relation to operational level specialists $(\mathrm{C})$ : he/she plans and organizes their work by means of creating an organizational structure adapted as per particular task and the managerial decision delivered from the higher level. The same department manager is also responsible for developing the system of motivation and incentives as well as control supervision. Finally, operational level specialists within our X model are traditionally responsible for efficient (timely and in full volume) performance of all posed assignments as per their competences and authority. With each other, these operational level specialists can be in both vertical and horizontal type of relations.

As it was already noted above, pyramid of operational specialists and that of project teams cooperate with each other (sometimes excluding managers from this cooperation). Occasionally, mutual rotation of staff between these pyramids may take place. Interestingly, promotion of an operational specialist to the upper level for further inclusion in a project may happen without direct participation of the related manager (white arrow in Figure 5), while moving a project team member back to the operational level nearly always involves participation of a manager (black arrows in the same Figure 5). Manager can easily return the "freed" member of team to his/her previous position of the operational specialist or can offer an alternative position but also within the organizational structure of the lower pyramid, taking into account the qualifications of this employee and the current strategic/tactical level necessities. The suggested here $\mathrm{X}$ model of the adaptive organizational structure for a corporate department does the following:

- It makes sure project teams and project groups are included into the overall structure of management. Under any of the previously applied models this integration would have had very low efficiency (due to inability of teams to influence the decision of managers and also due to very different attitude to responsibility of consultants and experts).

-It draws the line between three types of activities in any department - operational, managerial and creative. Moreover, it determines how they interact and prioritize in relation to each other.

-It guarantees that the organizational structure overall is headed by high-class professionals in the related field, which are members of project teams and project groups, however, it also makes sure managers have strong decisive powers.

- It provides extra opportunities for career promotion and staff rotation (both can be upon manager's decision just as with traditional career growth and also by the decision of a certain project team). In such a way, operational level specialist gets more chances for own development, while his/her department gets the much-needed flexibility along with the capacity to quickly mobilize the best human resources in case if a serious problem emerges.

- It reduces the number of levels between top management and workers of the operational level (due to the opportunity to interact directly and also due to use of mutual rotation between the operational level on the one side and project teams/groups on the other). In such a way, this type of structure becomes much flatter as compared to traditional hierarchical structures.

Figure 5 shows the proportional organizational structure, in it the size of two pyramids is more or less the same. In real bu siness practice though the actual size of these pyramids (and thus, also the number of the employed in each of them) are different. It would be quite logical to assume that in the virtual and technological fields of corporate activities the number of project teams' members (the upper inverted pyramid) outweighs the number of other employees, while in the material field of corporate activities the situation is exactly the opposite. 
As we have shown it in Figure 6, organizational structure, its shape and contents would be changing when changes take place in corporation's presence in a particular field (it is mostly material vs. virtual in our case with global tourism). Black arrows in Figure 6 show how managerial unit is gradually moving down to the basis of organizational structure. This is yet another proof that the department functioning primarily in the virtual field of TNC activities would be much flatter and flexible due to minimization of the operational specialists' number (and thus - due to less levels in management of the lower pyramid in our model). On the other hand, the department present mostly in the material field of activities would become more rigid in its hierarchy, more upward. Also, it would be much more regulated in all of its activities, the latter, in their turn, being strictly compliant with all standards.

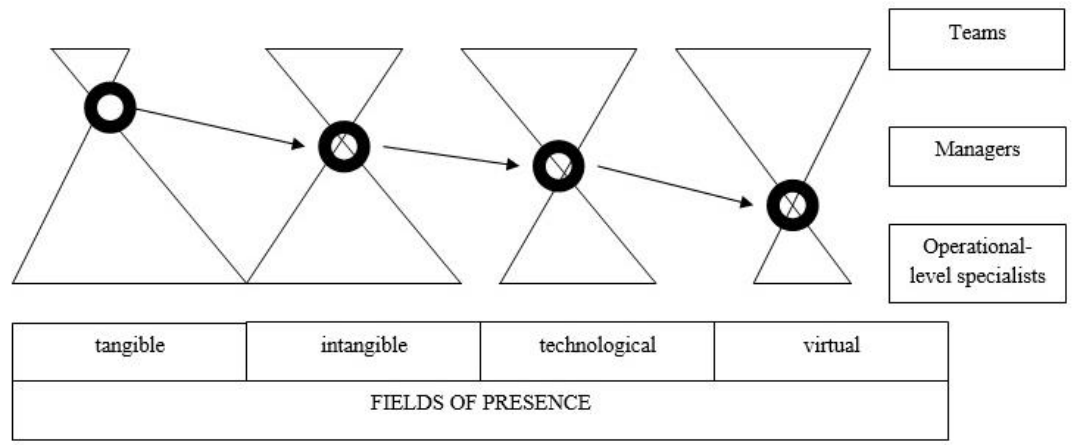

Figure 6. Transformation of the X model of organizational structure due to changes in department's presence (Source: developed by authors)

\section{Transnational Dynamics of Corporate Networks}

After we have considered the $\mathrm{X}$ model of adaptive organizational structure for a department as a unit within transnational corporation, it would be logical to determine also the model of interaction for all such units' functions within the same transnational corporation as a joint open socioeconomic system. As it was already determined above, general corporate strategy of development, uniting all structural units of a TNC, belongs to the responsibilities of top managers which in this X model take the central seat. Manager (or several of them) are supposed to concentrate all their efforts on the interaction of creative staff and operational level professionals. Managers also represent the interests of the related department in its interaction with other structural units and the core of a TNC. In other words, managers are responsible for maintaining the unity of a corporation in the course of full-swing interaction between various structural units with each other and with the core. Thus, managers serve as the guarantee for company's wholeness, for successful implementation of its general strategy, for protection of all stakeholders' rights, etc. Generally speaking, organizational structure of any tourism corporation has come its long way from a traditional, rather simplified geometry to a complex, highly sophisticated network (Taylor, 2013), in which managers stand at the crossroads of all connections. Therefore, we can state that today network structure of transnational corporation and networking principles in production processes' organization become the only efficient method of management which would be compliant to the requirements of the global market. In the first place, network structure is helpful because it can reduce the number of levels in the management structu re and it can also increase the flexibility of a corporation. Among quite many preconditions which provoked the speedy development of network structures among tourism TNCs we need to mention high dynamics of environmental changes and the necessity for quicker adaptation of companies to these changing conditions. Top management of today's tourism TNCs does not have the right to range departments as more or less important - thus, it does not provide immediate access to the middle level of management to coordinate them too. The rate of changes is too high, and all transnational corporations have to adapt to these quicker changes. This automatically means they can coordinate only at the highest level of management. Moreover, dynamic nature of the external environment factors leads to the same dynamism in priorities and importance of corporate activities carried out by various structural units (division/business zones). This means that a certain business zone which used to be secondary and/or not really relevant always has a chance to get much higher incomes so that to become the "champion" of a corporation (who is supposed actually to provide corporation's leapfrogging development). Since under current conditions it would be useless to range structural units, it is quite obvious that they can be "ranged" more or less equally, however, taking into account the following positions:

- Constant complication of both production and commercial activities, leading in its turn to complication of internal business processes and interactions. As the experience of many tourism corporations shows, launching and maintaining stable interaction between the departments as well as fixing business processes to certain regulations and competences seem to be inefficient. All interactions between structural units of a corporation must be open and free, each structural unit should have direct access (or the opportunity to have it) to all communication channel inside the company. Moreover, every structural unit should have the right and the capacity to initiate new channel, and if needed - this newer channel can be internal or external, with the immediate environment.

- Constant expansion of company's presence at the global tourism market. Contemporary tourism TNC should have all opportunities to expand its presence up to the limits of the market itself, including those opportunities related to buying out other forms of businesses (hotel chains, tour operators, agencies' network, etc.). Merging new forms of businesses, including those not involved directly in tourism services' production (the so-called non-related diversification) would be possible only in the case when the TNC has network structure. Network is able to "connect" the newly merged enterprises and organize their productive interaction with other businesses quicker than any other form of structuring. And noteworthy, this will not require large-scale and costly restructuring or other form of optimization.

- Growing autonomy in production activities of corporate structural units. This is one of the ways to increase company's competitiveness overall. As it has been already proved above, granting more autonomy to departments and strategic business zones inside a corporation (up to the level of independent development of their own business plans, determination of own mission, managing independently own resources, etc.) only increases the efficiency of activities overall. And thus, it also increases product competitiveness at both local and global markets. Absolute independence inside a corporation is not possible, of course, however, network structure itself promotes autonomy of all structural units, allowing them not only participate actively in the already existing corporate network but also create new networks (for example, the network of own loyal clients or the network of the affiliated tourist agents).

- Rapid development of computer technologies and global communications. Technological changes, those in telecommunications first of all, have allowed contemporary corporations, on the one hand, to "lose grip" in managing departments, thus letting structural units float freely. On the other hand, progress in communications has also allowed maintain strict (and often invisible) control over all activities inside structural units or between them. Intracorporate computer network is often the exact copy of general organizational network. This allows the 
corporate Board not to wait for a certain reporting period but simply check any activity of any structural unit, any time and from any location. Moreover, such monitoring can track down all activities to the level of a particular manager. These forms of control allow keeping all employees on a short leash, even if these employees are working on the opposite side of the planet, thousand miles away from the headquarters. This is also yet another reason why middle level of management and monitoring become not that necessary.

Finally, traditional horizontal and vertical interactions inside TNCs have been seriously transformed in the recent decade. The already classical relations "boss - subordinates" are being substituted by the relations of two (or more) co-owners of business, with a different set of authority and capacities (this is especially applicable for the case when manager and Board member are both shareholders of their enterprise). In this situation the employment contract of a manager can be understood as a standard purchase contract, under which professional knowledge of one person is being sold to others. Classical organizational structure used to be based on horizont al relations which in their turn were based on information exchange procedures, consulting and best practices' exchange. These forms of relations inside companies are being pushed out today by strategic partnerships, alliances and various other forms of unions. Therefore, today vertical relations inside a tourism TNC are turning into the interaction of two co-owners, both being financially interested in the success and further development of their common business since both depend on the business outcome of the chosen strategy implemen tation. At the same time, horizontal interactions between corporate departments are becoming similar to the relations between separate independent enterprises, they may have legal contracts signed with each other. Terminal units of contemporary TNCs become some sort of ports open for inclusion of new elements into the corporate network through the mechanisms of transnational alliances of various levels (Mikhailushkin and Shimko, 2005). For example, a network may unite suppliers of tourist services (hotels, airlines, etc.) with tour operators so that to implement a certain tourist project (popularization of a new destination, entering new market or widening own share at the older one, etc.). Once this project is over - its participants become disengaged so that to become elements of a new chain, for a new business project. Since all functions in this case are performed on the contractual basis, any participant involved in a deal can be easily substituted, if necessary. In the long term, this also leads to lower total costs of the network structure in general.

With an eye on changes in the external environment, corporation's board forms certain value chains which include nodes to coordinate all activities for higher efficiency of projects' implementation. Priority rate of a certain project predetermines the volume of investments carried out by the Board into the terminal units of a corporate network. Value chains are highly dynamic in nature, they are easily created, and can be same easily liquidated. Terminal units of a network inside the organizational structure of tourism TNC are interested in own independence and autonomy in actions. On the other hand, they are no less interested to be included and actively engaged in value chains formed by the corporate Board, since every new value chain is also an object of active and heavy investments from the Board. For this reason, terminal units try to look radically different on the background of all other network structure. They actively demonstrate their capacities and competences, they eagerly share knowledge, they are always ready to cooperate with other terminal units so that to increase the efficiency of business processes, etc. Network structures today rely more not on the administrative but rather on the market forms of resources' flows' management. The logic behind networking as an organizational structure for a TNC is that it forms its own, internal market and even the whole own market economy inside the company. The specific feature of such a market economy is that relations are being set not between fully independent from each other economic agents but between departments of the same corporation (though they also have quite high level of autonomy). This may sound strange but creating a network tourist TNC tries to localize market relations with the aim to resist the negative impacts from the external environment. On the one hand, network structuring allows TNCs participate more actively in all global trends, making the most of all advantages and chances for profit growth that the globalization offers. On the other hand, it demarcates inside-the-network relations from the rest of the world, thus contributing to corporation's stability while it reacts to various external manifestations.

The effect of localization created by the network structure, allows corporation reduce all business risks significantly and also guarantees the inclusion of the most trusted partners into the network. All interactions between the structural units of a network corporation are limited by the corporate "inside world", with its internal market protected from damaging actions of the outside participants. It is not that important which terminal unit is interacting with which structural department within the frameworks of a value chain formed by the Board. It is much more important that all partners are equal participants of the internal corporate market, any of them can be easily controlled and sanctioned if needed, while strictness and totality of these corporate reactions would be much stronger than that of national authorities. Localization as a consequence from introduction of network organizational structure allow corporations protect themselves from various political and economic attacks of national states. Network-based unions can easily impose pressure on national authorities, lobby own interests in governments, for example (and in the first place), in the issues concerning taxation and export-import operations. Network organizational structures provide all their members with a range of useful instruments which are used to neutralize the effects from state economic regulation. Apart from the already mentioned above advantages from markets' localization granted by network organizational structure of contemporary tourist TNCs, we need to mention also the potential advantages stemming from segmentation and monopolization of markets. One of the barriers for entering the sector (and leaving it) is limitation on participation in local networks. For example, if a tourism company or a hotel fails to get included into the network of sectorial TNC - this may lower its competitiveness significantly and may even make its further presence at a certain market impossible as such. On the other hand, inclusion in a network structure becomes the recipe for success, though it also leads to some sort of competitive selection between market subjects since in order to be welcomed in a network all companies are supposed to comply to a range of certain criteria introduced by the Board. Such selection is traditionally used by transnational tourist corporations when they are entering new markets or when they are trying to optimize their internal business processes. Fragme ntation of one common market space is caused by the network structure of relations inside a corporation and it has one more highly important dimension: lack of common legal spaces and thus, deficit of legal rights as such (Ushakov, 2017). Network-based TNC has its own rights and rules, and for all participants of these network relations intragroup norms are more meaningful than those imposed from the outside.

Contemporary tourism TNC can be thus presented as an open network in which terminal units are represented by departments and strategic business zones while the overall framework is constructed on the basis of X model. Location of terminal units cannot be exactly specified and regulated (as it is in hierarchical organizational structure) due to the fact that their interactions between each other and also with the Board is in the first place determined by the contents and the meanings inside value chains of the projects introduced and implemented by top management. This dynamic character of all organizational interactions inside a corporation is caused by the necessity to boost flexibility under the constantly changing conditions at the tourism market, and project approach to all interactions thus becomes integral part of all daily practices. Another reason why dynamic flexibility is so needed is because inside a corporate network there are numerous departments, sub-departments and project groups that are performing the same type of works on a regular basis.

The latter goes against the traditional principle of labor distribution and also prevents the formation of stable production-related interactions in transnational tourism business. For example, a tourist TNC may own several airlines, several hotel chains and a wide network of agencies. All these hotels, or all smaller tour agencies perform essentially the same functions, moreover, often they are competing with 
each other. When the Board is planning to launch another promising project (thus - creating a new value chain as well), it may add to this chain (or exclude from it) any network component as it deems fit, provided performance indicators of a particular structural unit match the requirements set to potential participants of this newer project. Presence of several similar departments within the general network structure is very convenient in this context since there is always a possibility to substitute one department with another. This is yet another contribution to flexibility and adaptive features of a corporation. Availability of choice also means the Board always has alternative variants at the table when considering new strategic projects and new value chains. This also gives the Board enough space for production restructuring and optimization (for example, reorganization of departments, sale or closure of those terminal units which can not be used anymore in any of the available value chains). At this, unity of a transnational corporate network is maintained due to the following:

- Each structural group or strategic business zone has its own top managers which together form the human frame of a company. It is these managers that maintain formation and functioning of a network structure. In geometrical terms, structural units are the dots connected with each other via intracorporate interactions which are the edges of this structure. Well-tuned horizontal and vertical connections are regulated by the intracorporate contracts and strategic partnerships, both serving to provide stability of a corporate network. Using skills and competences of top managers, the Board implements the general strategy, adding the needed departments to its general projects.

- Corporate code of conduct is closely followed and is equally applicable to all (managers, creative staff, operational-level professionals). A complex system of ethical and professional rules regulates the behavior of all employees and also, indirectly, propagates general corporate values and priorities.

- The key role of the Board is constant development and implementation of general corporate projects along with new value chain s. Once a new project along with its value chain are approved, the Board is supposed to decide which departments and units to include into this project. Depending on the importance of a project for corporation as a whole, the Board would also decide on the form and the frequency of reporting along with the system of indicators to be used by managers of structural units. In other words, the Board decides on the "length of the leash" for each division and each strategic business zone.

- TNC has all the instruments to increase/decrease entry/exit barriers in its corporate network as per particular participants.

- Transparency of intracorporate relations and external interactions.

Therefore, the model of corporate network structure has the following key features: minimal number of levels in management; dynamic internal interactions; non-regulated horizontal interactions; wide spread of strategic partnerships and contractual relations on horizontal levels of interactions inside a network; absence of fixed labor distribution inside a corporation; network structure serving as some sort of frame in which managers are the elements uniting departments and strategic business zones; overall openness of corporate network. Transnational corporations operating in tourism are not that different from various other corporations in their today's network structure. They also implement the networking approach, even outside the frameworks of own company, in relation to external environment as well. For example, they have network-like interaction with independent intermediaries, consumers of tourism product and even with state authorities. Let's take independent intermediaries, for example. They organize the distribution of tourist product of a TNC and they are predominantly small and mid-sized businesses since larger intermediaries (e.g., agent networks or popular Internet portals) would be of interest for a TNC too but not as partners - rather as potential objects for buying out and further integration into the network.

In relation to intermediaries among small and mid-sized business tourist corporations apply their usual networking practices, using the instruments of exclusive or regional representation, and also franchising and retailing schemes. In this case corporations tend to be rather generous in their investments or other forms of support for intermediary structures. Corporations are interested to raise their own agents and later form independent agent networks so that to boost the efficiency of sales and expand global representation. At later stages corporations may return to their usual methods, that is, buying out fully functioning businesses (with their independent brands or those already using their corporate brand, for example, according to a franchising deal). In the field of interactions with client's tourist TNCs also use networking with all related instruments. For example, they often found some sort of clubs of loyal clients, using their client loyalty programs. This form of interaction with clients help disseminate information about tourist product further, and this dissemination often takes place under the conditions of commission fee for the already active client (the most popular example is referral program, when clients recommend a company to other people, getting a discount or some sort of bonus in exchange).

For a multiproduct and diversified corporation (and most of TNCs in tourism are like this today) it is quite easy to implement all described above activities. They already know how to attract their client and how to make them stay, thus making this client loyal. Smaller tour operator has very little to offer to its regular clients. For example, if a small tour operator offers a hotel discount - most probably, this would be a discount for one hotel only, not a chain of hotels (which would have been a larger choice for a client). Smaller tour operator would not be able to discount on the flights of large airlines either. It can offer a bonus dinner in a restaurant affiliated to a particular hotel but it cannot offer a supermarket discount or a discount for gas at a local gasoline network. At the same time, a transnational company would be quite able to offer all of these and many other discounts and in such a way to encourage both partners and their clients (the latter being also the clients of this corporation) to purchase more. Networking with clients is integral part of functioning for any transnational company, including those working in tourism. The circle of their clients includes millions of people in dozens of countries worldwide, and for each individual among these millions the corporation is ready to offer something personal and special so that to boost the intensity of further consumption of services. And even in their relations with state authorities' transnational corporations are still able to use networking. TNCs can "implantate" their corporate interests into the state machinery. However, this would be possible only if a company finds at least one minor gap in the "legal fence" which traditionally stands between the state and the business. For example, there might be a public officer, for some reason, loyal to corporate ideas and values. In the future, this officer might find enough incentives to organize the whole system of lobbying, at all level of state administration, so that the interest of a tourist TNC are duly noted by the state or municipal authorities. Obviously, the higher is the rank of this "personally interested" public officer - the larger would be the gap for potential corporate lobbying and the larger network this public officer would be able to create so that to impose the interests of this corporation.

\section{CONCLUSIONS}

Forming their internal network structure, contemporary TNCs in the tourism sector are actually shaping their own market which automatically becomes an integral part of the global market due to the size of transnational corporations and the scope of their operations. The internal market inside a corporation is always protected from all potential negative influences from the outside (competi tors' actions, fluctuations in consumer demand, changes in state regulation, etc.). It is protected thanks to all advantages of localization and also due to the capacity of a corporation to intrude in any activity of its "independent" partner.

Once a client has joined the network of a particular corporation - they have two options for further movements: either to increase the intensity of consumption, making use at the same time of various preferences and incentives provided by the corporation in re turn; or to 
overcome the exit barriers (for example, if a client wants to change the tour operator, they would need to spend some time on search for information on the alternatives, on the analysis of this information, plus there is always a risk related to such a switch, etc.). Clients with dominating economic incentives would always choose the first of these options since this variant is obviously easier and does not require spending additional time and resources on it. Representatives of local and/or state authorities, cooperating (in some way) with a tourist TNC are also free to leave the network. However, in many cases this would automatically mean leaving the public post as well. And this condition is a serious exist barrier! Finally, representatives of local small and mid-sized businesses which once got access to the resources of a corporate network would never be really free again. Exit barriers created specifically for them simply destroy all further opportunities for independent economic activity. For example, there might be huge fines for leaving the network or moratorium on all future independent business operations may be specifically mentioned in a contract.

\section{REFERENCES}

Batkovskiy, A.M., Kalachikhin, P.A., Semenova, E.G., Telnov, Y.F., Fomina, A.V., \& Balashov, V.M. (2018). Configuration of enterprise networks. Enterpreneurship and Sustainability Issues, 6(1), 311-328. https://doi.org/10.9770/jesi.2018.6.1(19)

Chkalova, O., Efremova, M., Lezhnin, V., Polukhina, A., \& Sheresheva, M. (2019). Innovative mechanism for local tourism system management: A case study. Entrepreneurship and Sustainability Issues, 6(4), 2052-2067. https://doi.org/10.9770/jesi.2019.6.4(35)

Dunets, A.N., Vakhrushev, I.B., Sukhova, M.G., Sokolov, M.S., Utkina, K.M., \& Shichiyakh, R.A. (2019). Selection of strategic priorities for sustainable development of tourism in a mountain region: Concentration of tourist infrastructure or nature-oriented tourism. Entrepreneurship and Sustainability Issues, 7(2), 1217-1229. https://doi.org/10.9770/jesi.2019.7.2(29)

Fedyunin, D.V., Bezpalov, V.V., Lochan, S.A., Golovina, V.V., \& Ivanov, A.V. (2018a). Information support model for the children's leisure and tourism industry within the annual planning cycle. Journal of Environmental Management and Tourism, 9(6), 1256-1262. https://doi.org/10.14505//jemt.9.6(30).15

Fedyunin, D.V., Bezpalov, V.V., Lochan, S.A., Golovina, V.V., \& Karpova, N.D. (2018b). Methods of implementing PR campaigns for children's recreation and tourism at the federal and regional levels. Journal of Environmental Management and Tourism, 9(8), 1745-1750. https://doi.org/10.14505//jemt.v9.8(32).13

Goldsmith, R., \& Flynn, R. (1992). Identifying innovators in consumer product markets. European Journal of Marketing, 26(12), 42-45. https://doi.org/10.1108/03090569210022498

Gulyaev, V. (2003). Tourism: Economy and social development, Finansy i Statistika, Moscow, Russian Federation.

Herasymovych, I.A. (2018). Mechanisms and instruments of accounting engineering in the management of the enterprise's payment capacity. Economics. Finances. Law 3, 13-17. https://doi.org/10.657.471

Holstein, W. (1990). The stateless corporation, Business Week, New York, USA.

Kala, N., Abaydeldinov, Y., Furman, T., \& Ponomarev, A. (2017). The world tourism organization for countering terrorist threats. Journal of East Asia and International Law, 10(2), 549-550. https://doi.org/10.14330/jeail.2017.10.2.11

Kantemirova, M.A., Dzakoev, Z.L., Alikova, Z.R., Chedgemov, S.R., \& Soskieva, Z.V. (2018). Percolation approach to simulation of a sustainable network economy structure. Entrepreneurship and Sustainability Issues, 5(3), 502-513. https://doi.org/10.9770/jesi.2018.5.3(7)

Kostyukhin, Y. (2019). Conceptual provisions of sustainable development of socio-economic systems (on the example of an industrial enterprise). International Multidisciplinary Scientific GeoConference Surveying Geology and Mining Ecology Management, SGEM, 19, 131-138. https://doi.org/10.5593/sgem2019/5.3/S21.017

Lenskiy, E. (2001). Transnationalizations of capital, Armita - Marketing and Management, Volgograd, Russian Federation.

Mikhailushkin, A., \& Shimko, P. (2005). Economy of transnational company, High School, Moscow, Russian Federation.

Mikhaylov, A.S. (2018). Socio-spatial dynamics, networks and modelling of regional milieu. Entrepreneurship and Sustainability Issues, 5(4), 1020-1030. https://doi.org/10.9770/jesi.2018.5.4(22)

Mingaleva, Z., Sheresheva, M., Oborin, M., \& Gvarliani, T. (2017). Networking of small cities to gain sustainability. Entrepreneurship and Sustainability Issues, 5(1), 140-156. https://doi.org/10.9770/jesi.2017.5.1(12)

Movsesyan, A. (2001). Transnationalization in the world economy, Financial Academy under the Russia Government, Moscow, Russian Federation.

Muradl, N., \& Ahmadov, F. (2019). Managing contradiction and sustaining sustainability in inter organizational networks through leadership: A case study. Entrepreneurship and Sustainability Issues, 6(3), 1155-1069. https://doi.org/10.9770/jesi.2019.6.3(14)

Mussapirov, K., Djalkibaev, Kurenkeyeva, J.G., Kadirbergenova, A., Petrova, M., \& Zhakypbek, L. (2019). Business scaling through outsourcing and networking: selected case studies. Entrepreneurship and Sustainability Issues, 7(2), 1480-1495. https://doi.org/10.9770/jesi.2019.7.2(48)

Padilla, M.A.E., Handoyo, R.D., Sugiharti, L., \& Muryani, M. (2019). Production networks under The ASEAN Plus Six. A good deal or a threat? Entrepreneurship and Sustainability Issues, 7(1), 81-91. https://doi.org/10.9770/jesi.2019.7.1(7)

Panfiluk, E., \& Szymańska, E. (2017). The measurement of the innovativeness of health tourism services using an adequacy matrix title of the article. Entrepreneurship and Sustainability Issues, 4(4), 400-420. https://doi.org/10.9770/jesi.2017.4.4(1)

Prause, G., \& Atari, S. (2017). On sustainable production networks for industry 4.0. Entrepreneurship and Sustainability Issues, 4(4), 421-431. https://doi.org/10.9770/jesi.2017.4.4(2)

Prokofieva, M., Espenbetov, N., Shakirova, R., Lutherovich, O., \& Imangulova, T. (2017). Mountain tourism in Kazakhstan as an important factor of physical education, Espacios, 38(47), 1-9. https://doi.org/10.0798.1015

Provalova, E.V., Lukiyanova, M.N., Skrobotova, O.V., \& Ivanova, R.M. (2019). Prospects for the development of ecological tourism in specially protected natural areas of the Ulyanovsk Region. Journal of Environmental Management and Tourism, 10(4), 809-818. https://doi.org/10.14505/jemt.v10.4(36).11

Sarma, U., Karnitis, G., Zuters, J., \& Karnitis, E. (2019). District heating networks: enhancement of the efficiency. Insights into Regional Development, 1(3), 200-213. https://doi.org/10.9770/ird.2019.1.3(2)

Shevyakova, A., Munsh, E., \& Arystan, M. (2019). Information support for the development of tourism for the diversification of the economy of Kazakhstan. Insights into Regional Development, 1(2), 138-154. https://doi.org/10.9770/ird.2019.1.2(5)

Singgalen, Y.A., Sasongko, G., \& Wiloso, P.G. (2019). Community participation in regional tourism development: A case study in North Halmahera Regency - Indonesia. Insights into Regional Development,1(4), 318-332. https://doi.org/10.9770/ird.2019.1.4(3)

Šišulák, S. (2017). Userfocus - tool for criminality control of social networks at both the local and international level. Entrepreneurship and Sustainability Issues, 5(2), 297-314. https://doi.org/10.9770/jesi.2017.5.2(10)

Stepaniuk, K. (2018). Visualization of expressing culinary experience in social network, memetic approach. Entrepreneurship and Sustainability Issues, 5(3), 693-702. https://doi.org/10.9770/jesi.2018.5.3(21)

Tulbayeva, A., Abdikarimova, M., Ganitaev, M., Imangulova, T., \& Pestova, A. (2017). Optimization problems distribution of investments for the implementation strategy of domestic tourism in Kazakhstan. Espacios, 38(47), 1-7. https://doi.org/10.a17v38n47/a17v38n47p37

Ushakov, D. (2006). National tourism industry: Problems of development, Granitsa, Moscow, Russian Federation.

Ushakov, D. (2017). Information technologies within market economy: how communication tools became a field of activity. The EUrASEANs, 1, 7-18. https://doi.org/10.2539.5645

Van, H.T., Huu, A.T., \& Ushakov, D. (2017). Liberal reforms \& economic growth: Current issues and interrelations. Journal of International Studies, 10(4), 109-118. https://doi.org/10.14254/2071-8330.2017/10-4/8

Vlasov, A.I., Grigoriev, P.V., Krivoshein, A.I., Shakhnov, V.A., Filin, S.S., \& Migalin, V.S. (2018). Smart management of technologies: Predictive maintenance of industrial equipment using wireless sensor networks. Entrepreneurship and Sustainability Issues, 6(2), 489-502. https://doi.org/10.9770/jesi.2018.6.2(2)

Zhigir, A.A. (2020). Calculation of the economic effect of environmental measures. IOP Conference Series: Earth and Environmental Science, 421(7), 072002. https://doi.org/10.1088/1755-1315/421/7/072002 